\title{
Cardiac manifestations of idiopathic pulmonary fibrosis
}

\author{
Abhinav Agrawal ${ }^{1, *}$, Isha Verma ${ }^{1}$, Varun Shah ${ }^{2}$, Abhishek Agarwal ${ }^{3}$, Rutuja R Sikachi ${ }^{4}$ \\ ${ }^{1}$ Department of Medicine, Monmouth Medical Center, Long Branch, New Jersey, USA; \\ ${ }^{2}$ Department of Medicine, University of Miami/JFK Medical Center Palm Beach Regional GME Consortium, Atlantis, Florida, \\ USA; \\ ${ }^{3}$ Department of Medicine, Cooper University Hospital, Camden, New Jersey, USA; \\ ${ }^{4}$ Department of Anesthesiology, Lilavati Hospital \& Research Center, Mumbai, India.
}

\begin{abstract}
Summary Idiopathic pulmonary fibrosis (IPF) is a chronic, progressive, parenchymal disease of the lung with an estimated prevalence of $14-43$ per 100,000. Patient usually presents with coughing and exertional dyspnea, which can lead to acute respiratory failure. IPF has been associated with various co-morbidities such as lung cancer, emphysema, obstructive sleep apnea (OSA), GERD and multiple cardiovascular consequences. The cardiovascular manifestations of IPF include pulmonary hypertension, heart failure, coronary artery disease, cardiac arrhythmias \& cardiac manifestations of drugs used to treat IPF. This review will outline evidence of the association between IPF and cardiovascular conditions and attempt to provide insights into the underlying pathophysiology. We also discuss the impact of these cardiovascular diseases on patients with IPF including increased morbidity and mortality.
\end{abstract}

Keywords: Idiopathic pulmonary fibrosis, pulmonary hypertension, right heart failure, atrial fibrillation, arrhythmias, coronary artery disease

\section{Introduction}

Idiopathic pulmonary fibrosis (IPF) is a chronic, progressive, parenchymal disease of the lung with a median survival of 3-5 years after diagnosis. The course can be variable ranging from slow progression of the disease over years to rapid decline and death over a period of months (1). IPF has an estimated prevalence of 14-43 per 100,000 and is the most common idiopathic interstitial pneumonia (2). The incidence of IPF is increasing given the aging population and an increase in the diagnosis due to prevalent use of chest imaging (3).

The patient usually presents with coughing and exertional dyspnea, which can lead to acute respiratory failure. Findings on exam include "Velcro" like rales on lung exam and other signs of chronic lung disease. According to the American Thoracic Society/the

Released online in J-STAGE as advance publication April 25, 2016.

*Address correspondence to:

Dr. Abhinav Agrawal, Department of Medicine, Monmouth Medical Center, Long Branch, New Jersey, USA 07740.

E-mail:Abhinav72@gmail.com, abagrawal@barnabashealth.org
European Respiratory Society (ATS/ERS) statement on IPF (4), diagnosis is based on the presence of usual interstitial pneumonia (UIP) pattern on high-resolution computed tomography (HRCT), histology patterns and the exclusion of other known causes of interstitial lung disease (ILD). Thus a multi-disciplinary approach is involved in diagnosing these patients (4).

IPF has been associated with various co-morbidities such as lung cancer, emphysema, obstructive sleep apnea (OSA), GERD and multiple cardiovascular consequences. The cardiovascular manifestations of IPF include pulmonary hypertension, heart failure, coronary artery disease, cardiac arrhythmias \& cardiac manifestations of drugs used to treat IPF. This review will outline evidence of the association between IPF and cardiovascular conditions and attempt to provide insights into the underlying pathophysiology.

\section{Pulmonary hypertension $\&$ right heart failure in IPF}

Pulmonary Hypertension (PH) and Right heart failure (RHF) are very severe complications of IPF and contribute significantly to morbidity and mortality in IPF (5). Despite this, PH in IPF is not well studied 
except in severe IPF. PH is now defined as mean pulmonary arterial pressures (mPAP) more than or equal to $25 \mathrm{~mm} \mathrm{Hg}$ at rest, confirmed by right heart catheterization (RHC) (6). According to the updated Venice clinical classification of $\mathrm{PH}, \mathrm{PH}$ associated with IPF is categorized as group $3 \mathrm{PH}$, which includes $\mathrm{PH}$ in chronic lung disease and/or hypoxemia (7).

It has been very difficult to estimate the epidemiology of PH in IPF (PH-IPF). IPF is usually an insidious disease and usually diagnosed later in its course, which might lead to overestimation of incidence of $\mathrm{PH}$ in these patients. Also the accuracy of diagnosis of PH in IPF with transthoracic echocardiogram has been seriously questioned (8). Right heart catheterization (RHC), considered to be the gold standard in diagnosis of $\mathrm{PH}$, is invasive and inconvenient which has made it hard to study PH-IPF in longitudinal studies. Lastly, most of the data about PH-IPF comes from small cohort of patients who are referred for lung transplantation evaluation, which does not represent all patients with IPF. Lettieri et al. studied IPF patients who underwent RHC for lung transplant evaluation and found that $32 \%$ patients had PH (9). Patel et al. studied a similar population in their center and found that $22 \%$ patients had $\mathrm{PH}(10)$. More recently in the multicenter ARTEMIS-IPF trial of ambrisentan, RHC done to risk stratify patients showed that $10 \%$ of patients had $\mathrm{PH}$. This study was unique because it excluded the severely sick patients $(\mathrm{FVC}<50 \%$ baseline and extensive honeycombing), which gives us insight into prevalence of PH in mild IPF. Only $5 \%$ of the patient population developed PH during the follow up RHC at 48 weeks indicating that $\mathrm{PH}$ progresses slowly in mild, clinically stable patients with IPF (11).

Pulmonary vasculopathy in IPF has partly been attributed to hypoxia induced smooth muscle hypertrophy and collagen deposition in small pulmonary arteries, muscularization of arterioles and intimal proliferation of venules. Vascular destruction and obstruction due to progressive parenchymal fibrosis also contributes to this process. Thrombosis in situ in pulmonary arteries has also been observed. Increase in levels of cytokines like endothelin-1, Fibroblast growth factor beta, platelet derived growth factor lead to vascular remodeling contributing to $\mathrm{PH}$ (12).

Most of the symptoms of PH overlap with IPF making it difficult to diagnose PH-IPF unless there is high clinical suspicion. Physical signs like accentuated pulmonary heart sound, tricuspid regurgitation murmur and fixed splitting of S2 can bee seen in PH. Signs of right ventricular failure like elevated jugular venous pulse, peripheral edema and hepatomegaly can be seen in advanced cases. Signs of pulmonary hypertension on Computed tomography (CT) of the chest include right ventricular dilation (RVD, increased main pulmonary artery diameter greater than $29 \mathrm{~mm}$ and pulmonary artery diameter greater than that of aorta (13). The electrocardiogram (EKG) might show signs of RVD. These include ST wave depression or T wave inversions in leads associated with the RV. But neither CT scan nor EKG has enough accuracy for diagnosing PH$\operatorname{IPF}(14,15)$. Pulmonary function parameters have poor association with $\mathrm{PH}$ (5). A combination of decreased DLCO $(<40 \%)$ and need for supplemental oxygen is very specific (94\%) but not sensitive $(65 \%)$ in predicting PH (9). Transthoracic Echocardiogram (TTE) is a very useful non-invasive test to diagnose $\mathrm{PH}$ with sensitivity of $80-100 \%$ and specificity of $60-98 \%$. But in presence of chronic lung disease, TTE has significant limitations. Arcasoy et al. demonstrated that right ventricular systolic pressure (RVSP) could be estimated in less than $50 \%$ of patients with advanced lung diseases. In this study less than $37 \%$ of people who had PH on TTE were found to have PH on RHC (8). Plasma B type natriuretic peptide (BNP) may serve as a screening tool as it has more than $85 \%$ sensitivity and specificity in identifying $\mathrm{PH}$ in patients with chronic lung disease (16). But for now, RHC remains the gold standard in diagnosis of PH in IPF patients.

\section{Cardiac arrhythmias and IPF}

Atrial arrhythmias (AA) are the most commonly seen arrhythmias in patients with IPF. Amongst them, increased incidence of Atrial Fibrillation (AF) and Atrial Flutter (AFL) has been the most commonly reported arrhythmias in patients with IPF. Nielsen $e t$ al. did a systematic analysis in 2004 where increase incidence of atrial fibrillation was found postoperatively in patients who underwent lung transplant (17). The highest incidence of AF (55.9\%) was found in patients who underwent lung transplantation for IPF and IPF was found to be a significant predictor for AF (OR, 2.3; CI, 1.1 to $4.8 ; p=0.03$ ). Exclusion of the patients with previous history of AF did not lead to a significant change in the results. Azadani et al. did a retrospective analysis of the lung transplant patients to assess the predictors for atrial flutter (AFL) (18). Out of 269 patients who underwent lung transplant, 35 (13\%) patients developed AFL. Again, the incidence of AFL was found to be higher in patients with IPF at $65.7 \%$ (OR, 2.6, 95\% confidence interval 1.1 to $6.1, p=0.03)$. A second multivariate analysis showed IPF as an independent predictor for AFL (OR, 2.94; CI, 1.31-6.62; $p=0.009$ ) (4) (19). Orrego et al. also performed a retrospective analysis to determine the predictive factors of arrhythmias post-operatively in patients undergoing lung transplant (20). The incidence of AA was found to be $25.4 \%$ in 366 patients (AF $17.8 \%$ and AFL/SVT - 7.6\%). Multivariate analysis to determine the risk factors showed IPF as one of the significant causes (OR, 1.98, 95\% CI, 1.15 to $3.40 ; p$ $=0.013)$. The possible explanations for this increased incidence include native fibrosis from IPF making 
surgery difficult, increased age and the increased risk of coronary artery disease in patients with IPF. Shibata et al. studied patients with IPF and COPD over 5 years to assess the causal relationship between pulmonary function tests and the development of AF (19). They reported that both decrease in $\mathrm{FEV} \%$ (forced expiratory volume) (OR, 0.982; CI, 0.965 to $0.999 ; p<0.05)$ and FVC\% (functional vital capacity) (OR, 0.977; CI, 0.956 to $0.998 ; p<0.05)$ were independent risk factors for development of AF.

The postulated mechanisms for arrhythmias in these patients include the presence of hypoxia, elevation of pulmonary pressures, the risk of coronary artery disease and the presence chronic inflammation $(19,21)$. Hypoxia results in increased sympathetic activity thereby increasing the risk for arrhythmias. Elevated pulmonary pressures (pulmonary hypertension) can lead to increased incidence of arrhythmias. The trigger for AF is around pulmonary veins, so alteration of these hemodynamics might explain the increased risk. The increased risk of coronary artery disease and associated heart failure also leads to an increased of arrhythmias (22). Lastly, chronic inflammation associated with IPF leads to an increased level of cytokines such as Il-6 and TNF-a, which could act as a trigger for various arrhythmias (23).

\section{Coronary artery disease and IPF}

A number of studies have demonstrated a relation between coronary artery disease (CAD) and IPF. Kizer et al. showed that pulmonary fibrosis was associated with an increased incidence of CAD when compared to non-fibrotic lung diseases (OR, 2.18; 95\% CI, 1.17 to 4.06) (22). They hypothesized a causal relation wherein pulmonary fibrosis promotes atherosclerosis as evidenced by the increasing serum levels of interleukins, cytokines, circulating immune complexes and development of fibrosis in extra-pulmonary organs like the digits and mediastinum. Of the immune mediators, Interleukin-4 (IL-4), Interleukin-8 (IL-8) and tumor necrosis factor- $\alpha$ (TNF- $\alpha$ ) are common elements, responsible for angiogenesis, which are elevated in IPF. Clubbing, a common finding in IPF, involves neovascularization and fibroplasia, which is observed in both IPF and atherosclerosis. Hence the presence of fibro-proliferative process beyond the lungs and the presence of mediator molecules produced in these disorders might explain the possible mechanisms of increased atherogenesis in these patients. Other possible mechanism includes hypoxia causing worsening angina. It is also possible that the presence of a severe lung disease might lead the attention away from routine cardiovascular care with decreased primary and secondary prevention. This hypothesis is supported by the fact that people with IPF were less likely to receive statins and beta-blockers than the general population (24).
Izbicki et al. in their analysis showed that CAD was present in $28.6 \%$ of patients with lung fibrosis in comparison to $9.8 \%$ patients with emphysema (25). This was remarkable given the fact that almost $98 \%$ of patients in the emphysema group were smokers versus only $31 \%$ in the fibrosis group, thus eliminating smoking as a confounding factor. In a population based study, Hubbard et al. compared 920 cases of IPF with 3593 matched controls and found an increased risk of acute coronary syndrome (OR, $1.53 ; 95 \% \mathrm{CI}, 1.15$ to 2.03 ) and angina (OR, $1.84 ; 95 \% \mathrm{CI}, 1.48$ to 2.29 ) (24). During the follow up period, again there was an increased risk of acute coronary syndrome (RR, $3.14 ; 95 \%$ CI, 2.02 to 4.87 ) with the mean follow up of 2.7 years from the date of diagnosis of IPF. In a comparative study between transplant candidates for COPD and IPF, Nathan et al. showed that the prevalence of CAD was found to be $65.8 \%$ in the IPF group compared to $46.1 \%$ in patients with COPD ( $p<$ 0.028) (26).

Cicchitto et al. suggest performing an extensive Cardiopulmonary Exercise Testing (CPET) in patients with IPF not only for identifying useful prognostic parameters, but also to detect potentially treatable cardiovascular alterations. However further studies are needed to better assess the cost and benefits of routine CPET testing in all IPF patients (27). The value of coronary calcification on chest computed tomography (CT) as a marker for CAD in patients with IPF was evaluated by Nathan et al. which showed that the sensitivity of moderate to severe calcification for significant coronary artery disease was $81 \%$ while the specificity was $85 \%$ with an associated odds ratio of 25.2 (4.64 to $166, p<0.005)(28)$. Thus the presence of coronary calcification on chest CT's in patients with IPF can indicate the need for further cardiac workup to assess for the presence of CAD.

\section{Drugs to treat IPF and their effects on the heart}

Evidence-based guidelines for the diagnosis and management of IPF were published in 2011 (29) and were recently updated in 2015 based on a multidisciplinary panel review of articles published in the interim (4). No medication till date has been shown to cure IPF but two new drugs; Pirfenidone and Nintedanib have shown to slow disease progression in clinical trials.

The ASCEND study group studied Pirfenidone in 555 patients with IPF in a phase 3 randomized controlled trial (RCT) and when compared with placebo, Pirfenidone reduced disease progression, as reflected by lung function, exercise tolerance, and progression-free survival, in patients with idiopathic pulmonary fibrosis. The side effect profile of Pirfenidone mainly included gastrointestinal side effects but no cardiac side effects were reported (30) and the same results were found in the CAPACITY trial, which was performed in 113 
centers in 13 countries (31). Patients who completed the CAPACITY studies were eligible to enter the ongoing open-label, long-term, follow-up extension study, RECAP and an interim analysis done in August 2013 showed a similar side effect profile to the CAPACITY trials and again without cardiac side effects (32). A comprehensive analysis of safety outcomes performed by Lancaster et al. in a large and well-defined cohort of 1299 patients with IPF who were followed prospectively for up to 9.9 years demonstrated that long-term treatment with Pirfenidone is safe and generally well tolerated and again without any cardiac side effects (33). Pirfenidone when studied in animal models has in fact been found to have a beneficial effect on myocardial infarction, atrial fibrillation and diabetic cardiomyopathy. This is believed to be due to a 2 prong mechanism in which it not only reduces the myocardial fibrosis and stiffness but it also stimulates the L-Type voltage gated $\mathrm{Ca}^{2+}$ channels which are pivotal in the excitation contraction coupling and thus helping systolic function (34).

Nintedanib, studied in the INPULSIS ${ }^{\circledR} 1 \& 2$ and also in the TOMORROW trial, was associated with a trend toward decline in lung function with fewer exacerbations (35). The adverse effect profile of Nintedanib was also primarily gastrointestinal but cardiac events were also reported. $9.7 \%$ of patients in the INPULSIS ${ }^{\circledR}-1$ study group were found to have a cardiac adverse event while $10.3 \%$ of patients were found to a cardiac adverse event in the INPULSIS ${ }^{\circledR}-2$ study group. These events were fatal in $0.3 \%(1 / 30)$ and $0.6 \%(2 / 34)$ of patients in the INPULSIS ${ }^{\circledR} 1 \& 2$ study groups respectively. Ischemic heart disease was also reported in $4.2 \%$ and $4.3 \%$ of patients in the INPULSIS ${ }^{\circledR} 1 \& 2$ study groups respectively (36).

Other medications studied for the treatment of IPF include a RCT comparing a combination therapy of prednisone, azathioprine and $\mathrm{N}$-Acetylcysteine versus placebo. It showed an increased risk of death and hospitalizations thus recommending against the use of this combination for the treatment of IPF. It also showed cardiac adverse events in $3 / 77$ patients in the treatment $\operatorname{arm}(37)$.

\section{Impact of cardiac manifestations of IPF}

IPF is a life threatening disease. The median survival of patients with IPF is 2.5 to 3.5 years (38). Age, sex, ethnicity, smoking are the common predictors of mortality in IPF. Although, the most common cause of death in IPF patients is respiratory failure from progression of the disease, death due to cardiac disease have been reported in the patients (26). It has a significant impact on the mortality and hospitalizations related to IPF (Table 1).

Presence of PH in IPF is associated with increased morbidity and mortality. Lettieri et al. showed presence of PH in IPF was associated with a significant decrease
Table 1. Cardiac Manifestations of Idiopathic Pulmonary Fibrosis

Pulmonary hypertension

Right sided heart failure

Arrhythmias

- Atrial Fibrillation

- Atrial Flutter

- Supraventricular tachycardia

- Multifocal atrial tachycardia

- Other atrial arrhythmias

Coronary artery disease

Cardiac manifestations of drugs used to treat IPF

in exercise capacity, as measured by a 6 minute walking test (6MWD) (9). Patel et al. found similar results in patients undergoing evaluation for transplant (10). Nadrous et al. showed that patients with RVSP $>50 \mathrm{~mm}$ hg had significantly worse survival (39). Lettieri et al. also showed that presence of $\mathrm{PH}$ was associated with significantly higher 1 year mortality rates (9). Presence of $\mathrm{PH}$ also has an impact on transplant outcomes in patients with advanced lung disease. Whelan et al. showed that increased PAP is associated with increased 90-day mortality post single-lung transplantation and 30day mortality post double-lung transplant in patients with IPF (40).

The presence of associated cardiovascular comorbidity can significantly reduce the survival and outcomes in the IPF patients who undergo lung transplantation. Orrego et al. studied the effect of atrial arrhythmias on outcomes and mortality of IPF patients who underwent lung transplant (20). The oneyear mortality rate was found to be higher $(21.5 \%)$ in AA group compared to the one without AA (15.7\%) $(p<0.05)$. Also, length of the stay in the hospital (morbidity) was increased with presence of AA (median: 20 days) compared to the patients with AA (median: 15 days) $(p<0.0001)$. Nielsen et al. demonstrated a similar increase in morbidity and mortality in patients with atrial arrhythmias amongst IPF patients after lung transplantation (17). The presence of AF led to increased the length of stay, $(32.4 \pm 60.0$ days $v s .17 .5 \pm 24.1$ days, $p=0.04$ ) increased in-hospital deaths (OR, 5.7; CI, 2.1 to $15.1 ; p=0.0005)$ and an increase in the chances of tracheostomy (OR, 3.6; CI, 1.8 to $7.3 ; p=0.0003)$ in these patients.

Presence of CAD also has a significant effect on the outcomes of IPF patients who undergo lung transplantation. Nathan et al. showed that outcomes of IPF patients with significant CAD was worse than those with no or non-significant disease $(p<0.003)$ with a median survival of 572 days from the time of left heart catheterization (26).

\section{Conclusion}

Cardiac disease has a significant effect on the mortality of IPF patients. Dyspnea and hypoxia from 
cardiovascular disease can be masked in these patients. On the other hand, cardiac disease can be worsened by hypoxia and pulmonary hypertension from the IPF. It is prudent to monitor these patients for cardiac manifestations and cardiac events to reduce the overall morbidity and mortality.

\section{References}

1. King TE Jr, Tooze JA, Schwarz MI, Brown KR, Cherniack RM. Predicting survival in idiopathic pulmonary fibrosis: Scoring system and survival model. Am J Respir Crit Care Med. 2001; 164:1171-1181.

2. Raghu G, Weycker D, Edelsberg J, Bradford WZ, Oster G. Incidence and prevalence of idiopathic pulmonary fibrosis. Am J Respir Crit Care Med. 2006; 174:810-816.

3. Raghu G, Chen SY, Yeh WS, Maroni B, Li Q, Lee YC, Collard HR. Idiopathic pulmonary fibrosis in US Medicare beneficiaries aged 65 years and older: Incidence, prevalence, and survival, 2001-11. Lancet Respir Med. 2014; 2:566-572.

4. Raghu G, Rochwerg B, Zhang Y, et al. An Official ATS/ ERS/JRS/ALAT Clinical Practice Guideline: Treatment of Idiopathic Pulmonary Fibrosis. An Update of the 2011 Clinical Practice Guideline. Am J Respir Crit Care Med. 2015; 192:e3-19.

5. Nathan SD, Noble PW, Tuder RM. Idiopathic pulmonary fibrosis and pulmonary hypertension: Connecting the dots. Am J Respir Crit Care Med. 2007; 175:875-880.

6. Hoeper MM, Bogaard HJ, Condliffe R, Frantz R, Khanna D, Kurzyna M, Langleben D, Manes A, Satoh T, Torres F, Wilkins MR, Badesch DB. Definitions and diagnosis of pulmonary hypertension. J Am Coll Cardiol. 2013; 62:D42-50.

7. Simonneau G, Gatzoulis MA, Adatia I, Celermajer D, Denton C, Ghofrani A, Gomez Sanchez MA, Krishna Kumar R, Landzberg M, Machado RF, Olschewski H, Robbins IM, Souza R. Updated clinical classification of pulmonary hypertension. J Am Coll Cardiol. 2013; 62:D34-41.

8. Arcasoy SM, Christie JD, Ferrari VA, Sutton MS, Zisman DA, Blumenthal NP, Pochettino A, Kotloff RM. Echocardiographic assessment of pulmonary hypertension in patients with advanced lung disease. Am J Respir Crit Care Med. 2003; 167:735-740.

9. Lettieri CJ, Nathan SD, Barnett SD, Ahmad S, Shorr AF. Prevalence and outcomes of pulmonary arterial hypertension in advanced idiopathic pulmonary fibrosis. Chest. 2006; 129:746-752.

10. Patel NM, Lederer DJ, Borczuk AC, Kawut SM. Pulmonary hypertension in idiopathic pulmonary fibrosis. Chest. 2007; 132:998-1006.

11. Raghu G, Behr J, Brown KK, et al. Treatment of idiopathic pulmonary fibrosis with ambrisentan: A parallel, randomized trial. Ann Intern Med. 2013; 158:641-649.

12. Agostini C, Gurrieri C. Chemokine/cytokine cocktail in idiopathic pulmonary fibrosis. Proc Am Thorac Soc. 2006; 3:357-363.

13. Ng CS, Wells AU, Padley SP. A CT sign of chronic pulmonary arterial hypertension: The ratio of main pulmonary artery to aortic diameter. J Thorac Imaging. 1999; 14:270-278.

14. Galie N, Humbert M, Vachiery JL, et al. 2015 ESC/ERS Guidelines for the diagnosis and treatment of pulmonary hypertension: The joint task force for the diagnosis and treatment of pulmonary hypertension of the European society of cardiology (ESC) and the European respiratory society (ERS): Endorsed by: association for European paediatric and congenital cardiology (AEPC), international society for heart and lung transplantation (ISHLT). Eur Heart J. 2016; 37:67-119.

15. Zisman DA, Karlamangla AS, Ross DJ, Keane MP, Belperio JA, Saggar R, Lynch JP, 3rd, Ardehali A, Goldin J. High-resolution chest CT findings do not predict the presence of pulmonary hypertension in advanced idiopathic pulmonary fibrosis. Chest. 2007; 132:773-779.

16. Leuchte HH, Baumgartner RA, Nounou ME, Vogeser M, Neurohr C, Trautnitz M, Behr J. Brain natriuretic peptide is a prognostic parameter in chronic lung disease. Am J Respir Crit Care Med. 2006; 173:744-750.

17. Nielsen TD, Bahnson T, Davis RD, Palmer SM. Atrial fibrillation after pulmonary transplant. Chest. 2004; 126:496-500.

18. Azadani PN, Kumar UN, Yang Y, Scheinman MM, Hoopes CW, Marcus GM, Rifkin C, Olgin JE, Lee BK. Frequency of atrial flutter after adult lung transplantation. Am J Cardiol. 2011; 107:922-926.

19. Shibata Y, Watanabe T, Osaka D, et al. Impairment of pulmonary function is an independent risk factor for atrial fibrillation: The Takahata study. Int J Med Sci. 2011; 8:514-522.

20. Orrego CM, Cordero-Reyes AM, Estep JD, Seethamraju $\mathrm{H}$, Scheinin S, Loebe M, Torre-Amione G. Atrial arrhythmias after lung transplant: Underlying mechanisms, risk factors, and prognosis. J Heart Lung Transplant. 2014; 33:734-740.

21. Patane S, Marte F, Sturiale M, Dattilo G, Luzza F. Atrial flutter, ventricular tachycardia and changing axis deviation associated with scleroderma. Int J Cardiol. 2011; 153:e25-28.

22. Kizer JR, Zisman DA, Blumenthal NP, Kotloff RM, Kimmel SE, Strieter RM, Arcasoy SM, Ferrari VA, Hansen-Flaschen J. Association between pulmonary fibrosis and coronary artery disease. Arch Intern Med. 2004; 164:551-556.

23. Kowalewski M, Urban M, Mroczko B, Szmitkowski M. Proinflammatory cytokines (IL-6, TNF-alpha) and cardiac troponin I (cTnI) in serum of young people with ventricular arrhythmias. Pol Arch Med Wewn. 2002; 108:647-651. (in Polish)

24. Hubbard RB, Smith C, Le Jeune I, Gribbin J, Fogarty AW. The association between idiopathic pulmonary fibrosis and vascular disease: A population-based study. Am J Respir Crit Care Med. 2008; 178:1257-1261.

25. Izbicki G, Ben-Dor I, Shitrit D, Bendayan D, Aldrich TK, Kornowski R, Kramer MR. The prevalence of coronary artery disease in end-stage pulmonary disease: Is pulmonary fibrosis a risk factor? Respir Med. 2009; 103:1346-1349.

26. Nathan SD, Basavaraj A, Reichner C, Shlobin OA, Ahmad S, Kiernan J, Burton N, Barnett SD. Prevalence and impact of coronary artery disease in idiopathic pulmonary fibrosis. Respir Med. 2010; 104:1035-1041.

27. Cicchitto G, Musella V, Acitorio M, Capuano N, Fiorenzano G, Owen CA, Polverino M, Polverino F. Idiopathic pulmonary fibrosis and coronary artery disease. Multidiscip Respir Med. 2014; 9:31.

28. Nathan SD, Weir N, Shlobin OA, Urban BA, Curry CA, 
Basavaraj A, Ahmad S, Kiernan J, Sheridan MJ, Earls JP. The value of computed tomography scanning for the detection of coronary artery disease in patients with idiopathic pulmonary fibrosis. Respirology. 2011; 16:481486.

29. Raghu G, Collard HR, Egan JJ, et al. An official ATS/ ERS/JRS/ALAT statement: Idiopathic pulmonary fibrosis: Evidence-based guidelines for diagnosis and management. Am J Respir Crit Care Med. 2011; 183:788-824.

30. King TE Jr, Bradford WZ, Castro-Bernardini S, et al. A phase 3 trial of pirfenidone in patients with idiopathic pulmonary fibrosis. N Engl J Med. 2014; 370:2083-2092.

31. Noble PW, Albera C, Bradford WZ, Costabel U, Glassberg MK, Kardatzke D, King TE Jr, Lancaster L, Sahn SA, Szwarcberg J, Valeyre D, du Bois RM, Group CS. Pirfenidone in patients with idiopathic pulmonary fibrosis (CAPACITY): Two randomised trials. Lancet. 2011; 377:1760-1769.

32. Costabel U, Albera C, Bradford WZ, Hormel P, King TE Jr, Noble PW, Sahn SA, Valeyre D, du Bois RM. Analysis of lung function and survival in RECAP: An open-label extension study of pirfenidone in patients with idiopathic pulmonary fibrosis. Sarcoidosis Vasc Diffuse Lung Dis. 2014; 31:198-205.

33. Lancaster L, Albera C, Bradford WZ, et al. Safety of pirfenidone in patients with idiopathic pulmonary fibrosis: Integrated analysis of cumulative data from 5 clinical trials. BMJ Open Respir Res. 2016; 3:e000105.

34. Avila G, Osornio-Garduno DS, Rios-Perez EB, RamosMondragon R. Functional and structural impact of pirfenidone on the alterations of cardiac disease and diabetes mellitus. Cell Calcium. 2014; 56:428-435.

35. Richeldi L, Costabel U, Selman M, Kim DS, Hansell DM, Nicholson AG, Brown KK, Flaherty KR, Noble PW, Raghu G, Brun M, Gupta A, Juhel N, Kluglich M, du Bois RM. Efficacy of a tyrosine kinase inhibitor in idiopathic pulmonary fibrosis. N Engl J Med. 2011; 365:1079-1087.

36. Richeldi L, du Bois RM, Raghu G, et al. Efficacy and safety of nintedanib in idiopathic pulmonary fibrosis. $\mathrm{N}$ Engl J Med. 2014; 370:2071-2082.

37. Idiopathic Pulmonary Fibrosis Clinical Research N, Raghu G, Anstrom KJ, King TE Jr, Lasky JA, Martinez FJ. Prednisone, azathioprine, and N-acetylcysteine for pulmonary fibrosis. N Engl J Med. 2012; 366:1968-1977.

38. Ley B, Collard HR, King TE Jr. Clinical course and prediction of survival in idiopathic pulmonary fibrosis. Am J Respir Crit Care Med. 2011; 183:431-440.

39. Nadrous HF, Pellikka PA, Krowka MJ, Swanson KL, Chaowalit N, Decker PA, Ryu JH. Pulmonary hypertension in patients with idiopathic pulmonary fibrosis. Chest. 2005; 128:2393-2399.

40. Whelan TP, Dunitz JM, Kelly RF, Edwards LB, Herrington CS, Hertz MI, Dahlberg PS. Effect of preoperative pulmonary artery pressure on early survival after lung transplantation for idiopathic pulmonary fibrosis. J Heart Lung Transplant. 2005; 24:1269-1274.

(Received April 13, 2016; Revised April 20, 2016 ; Accepted April 21, 2016) 